\title{
Socio-demographic and clinical characteristics of re-presentation to an Australian inner-city emergency department: implications for service delivery
}

\author{
Gaye Moore*1,2, Marie Gerdtz ${ }^{1}$, Elizabeth Maniass ${ }^{1}$, Graham Hepworth ${ }^{3}$ and \\ Andrew Dent ${ }^{2}$
}

\author{
Address: ${ }^{1}$ The School of Nursing, The University of Melbourne, Parkville, Melbourne, Australia, ${ }^{2}$ Emergency Department, St Vincent's Hospital \\ Melbourne, Victoria Parade, Melbourne, Australia and ${ }^{3}$ Statistical Consulting Centre, The University of Melbourne, Parkville, Melbourne, Australia \\ Email: Gaye Moore* - dgmoore@optusnet.com.au; Marie Gerdtz - gerdtzmf@unimelb.edu.au; Elizabeth Manias - emanias@unimelb.edu.au; \\ Graham Hepworth - g.hepworth@ms.unimelb.edu.au; Andrew Dent - Andrew.Dent@svhm.org.au \\ * Corresponding author
}

Published: 10 November 2007

BMC Public Health 2007, 7:320 doi:10.1 186/147/-2458-7-320

This article is available from: http://www.biomedcentral.com/I47I-2458/7/320

(c) 2007 Moore et al; licensee BioMed Central Ltd.

This is an Open Access article distributed under the terms of the Creative Commons Attribution License (http://creativecommons.org/licenses/by/2.0), which permits unrestricted use, distribution, and reproduction in any medium, provided the original work is properly cited.

\begin{abstract}
Background: People who have complex health care needs frequently access emergency departments for treatment of acute illness and injury. In particular, evidence suggests that those who are homeless, or suffer mental illness, or have a history of substance misuse, are often repeat users of emergency departments. The aim of this study was to describe the socio-demographic and clinical characteristics of emergency department re-presentations. Re-presentation was defined as a return visit to the same emergency department within 28 days of discharge from hospital.
\end{abstract}

Methods: A retrospective cohort study was conducted of emergency department presentations occurring over a 24-month period to an Australian inner-city hospital. Characteristics were examined for their influence on the binary outcome of re-presentation within 28 days of discharge using logistic regression with the variable patient fitted as a random effect.

Results: From 64, 147 presentations to the emergency department the re-presentation rate was $18.0 \%$ (n $=11,559)$ of visits and $14.4 \%(5,894 / 40,942)$ of all patients. Median time to re-presentation was 6 days, with more than half occurring within one week of discharge $(60.8 \% ; n=6,873)$, and more than threequarters within two weeks $(80.9 \% ; n=9,15 \mathrm{I})$. The odds of re-presentation increased three-fold for people who were homeless compared to those living in stable accommodation (adjusted OR 3.09; $95 \% \mathrm{Cl}, 2.83$ to 3.36). Similarly, the odds of re-presentation were significantly higher for patients receiving a government pension compared to those who did not (adjusted OR I.73; $95 \%$ Cl, I.63 to I.84), patients who left partway through treatment compared to those who completed treatment and were discharged home (adjusted OR I.64; $95 \% \mathrm{Cl}$, I.36 to I.99), and those discharged to a residential-care facility compared to those who were discharged home (adjusted OR I.46: $95 \% \mathrm{Cl}$, I.03 to 2.06 ).

Conclusion: Emergency department re-presentation rates cluster around one week after discharge and rapidly decrease thereafter. Housing status and being a recipient of a government pension are the most significant risk factors. Early identification and appropriate referrals for those patients who are at risk of emergency department re-presentation will assist in the development of targeted strategies to improve health service delivery to this vulnerable group. 


\section{Background}

A relatively small proportion of frequent emergency department (ED) users continue to account for a significant number of all ED visits and consume a disproportionate amount of resources [1-6]. Although not the principal cause of overcrowding, frequent ED attenders may exacerbate the problems by increasing demand for acute care services in a climate of limited resources $[7,8]$.

The literature describes well the characteristics of frequent ED users $[1,2,9-20]$. This group comprises a mix of people, including those with chronic health problems and psycho-social issues $[2,14,19,21]$. Despite their demographic heterogeneity, studies of frequent ED users do show that they are a vulnerable group $[14,16]$. For example, they are known to have complex care needs [2,9$12,14,22-24]$, suffer a higher incidence of mental illness [13], injury [25], morbidity and mortality $[12,13]$, and experience greater social disadvantage $[9,10,12,14,21]$ and homelessness $[20,24]$ than infrequent ED users.

Multiple users are defined by a range of time intervals that range from 48 hours to 120 days [26-31] Patients that return to the ED within 48 to 72 hours have a high risk of error in diagnosis [27]. Specific focus has been placed on elderly patients who have a high rate of return visits to the ED due to their advanced age, isolation, lack of support and poor health [31-35]. These findings are supported by a systematic review conducted by McCusker et al [36] utilising Andersen's behavioural model of service to determinate key factors of ED utilisation.

Furthermore, what constitutes appropriate ED use has not been well defined [8,37], and ED re-presentation has multiple time frames. For example, definitions of frequent use vary from three [38], to twelve visits per year [2,37,39-43]. In contrast, hospital re-admission has been defined as any admission occurring 28 days from discharge, but there is still a lack of agreement about the choice of an appropriate interval $[44,45]$. Research has determined risk factors associated with hospital re-admission $[2,12,19,44,45]$, and risk factors of return visits to ED for the elderly [28$34,36]$. Information on risk factors for re-presentation to the ED focus on quality of care issues such as deficiency in medical management $[26,27,46,47]$. In addition to counting overall numbers of ED visits per patient per annum, identifying people who re-present to a health service within 28 days is another way of measuring service use. The latter approach to analysis is important because it can capture those people who return to the ED for further treatment within a discrete time frame. Measuring ED service use in this way has the potential to provide a better understanding of frequent ED users and their socio-demographic and clinical characteristics. Indeed, recent research suggests that frequent ED visits may not simply be a reflection of a system unable to properly treat an illness or injury, or a lack of primary care, but rather, a function of complex, interrelated clinical, psycho-social and patient factors $[23,43]$.

The aim of this study was to describe the characteristics of people who re-present to the ED, and identify what factors differentiate these people from those who do not represent.

\section{Methods \\ Study Design}

We examined 24 months of data for all attendances at one $\mathrm{ED}$. The definition of re-presentation was established as attendance at the same ED within 28 days from discharge date from hospital (either from the ED or inpatient unit). This definition of re-presentation is congruent with that of hospital re-admission, which is also defined as occurring within 28 days of discharge.

We used a cohort design to extract and retrospectively analyze contemporaneously collected information from a database of ED presentations to one inner-city ED over a 24-month time frame. The 24-month time frame allowed for the possibility that seasonal differences might influence ED attendance rates. Since October 1995, all publicly-funded EDs within the jurisdiction where this study was conducted, are required to provide standardized information about ED presentations to the State Government through the Emergency Minimum Dataset (EMD) [48]. At the study site, reporting to the EMD is facilitated by the Patient Administration System (PAS), which includes clinical data collected for the use of the service. Data collection practices have been refined to be practical from both a clinical and an organizational perspective.

The study was approved by the Human Research Ethics Committee (HREC) of the health service in which it was conducted. The protocol was subsequently registered as a project with external approval by the collaborating university HREC.

\section{Setting}

The hospital in which this study was carried out is located in a large Australian city with a population of 3.5 million people. The hospital receives its income from State and Federal Government funding and is located within $5 \mathrm{~km}$ of the central business district. It is a major teaching hospital, with an ED attendance rate of approximately 32,000 per annum.

\section{Selection of Participants}

Participants included all patients who attended the ED during the study period (January 1, 2003 - December 31, 2004). The only exclusion criteria for the study were 
patients who had a discharge outcome of death. We considered the inclusion of admitted patients a key factor in the study design since admitted patients often have complex healthcare needs that have implications for discharge planning. Those presentations in December 2004 that had subsequent re-presentation in January 2005 were identified and included in the study. Patient data were retrospectively accessed for analysis from the PAS.

\section{Methods of Measurement}

Data in the PAS contain a unique patient identifier code (unit record number) and detailed demographic and clinical information for each ED presentation. In this study the unit record number was used to classify patients into two primary groups; re-presentation to the ED within 28 days of discharge from hospital or no re-presentation. Missing data from PAS were identified when frequencies showed either inconsistent results or missing information. For analysis, missing data were entered into a category labeled as "unknown".

A standardized data abstraction tool was devised by identifying the key variables and their defined categories within the EMD and replicating this information into a Microsoft Access program (Version 2003, Redmond, Washington). The variables and defining categories that were used in the EMD are displayed in Tables 1, 2, 3, and 4 .

For this study, homelessness comprised various living arrangements such as residing in a public place, a boarding house/hostel, a homeless shelter or having no fixed address. For each ED presentation at the study site, information about housing status was captured in the PAS by the variable, usual accommodation. To ensure the accuracy of this variable the patients identified as homeless had further examination of their medical records to confirm and identify the level of homelessness.

For the purpose of analysis, Chamberlain's [49] classification of housing status was used to create five categories. Primary homelessness included people living on the streets or in squats. Secondary homelessness included people living in crisis accommodation. Tertiary homelessness included people living in boarding houses. Marginalized housing included people residing in public housing requiring rental assistance or those with other unstable rental arrangements. Stable housing included people living in permanent accommodation.

\section{Data Collection and Processing}

Due to the volume of data generated by an electronic report over the 24-month period, three abstractors were used to collate the data for those patients who were homeless. Training was conducted over two days and review of abstractor accuracy was performed on a daily basis. One abstractor took the position of leader in the data collection process and examined $80 \%$ of all data collected. All abstractors were blinded to the etiologic relationships being investigated in the study.

The abstractors conducted an independent review of the first 20 medical records for the purpose of determining inter-rater reliability. Inter-rater reliability was examined in the coding of the homeless variable. The percentage of

Table I: Demographic characteristics of all patients who presented to the emergency department from Ist January 2003 to 3 I st December $2004(n=40,942)$.

\begin{tabular}{|c|c|c|}
\hline Variable & No & $\%$ \\
\hline \multicolumn{3}{|l|}{ Age (years) } \\
\hline$<=25$ & 8745 & 21.4 \\
\hline 26 to 35 & 9297 & 22.7 \\
\hline 36 to 45 & 5527 & 13.5 \\
\hline 46 to 55 & 4483 & 10.9 \\
\hline 56 to 65 & 3955 & 9.7 \\
\hline$>65$ & 8935 & 21.8 \\
\hline \multicolumn{3}{|l|}{ Gender } \\
\hline Male & 22391 & 54.7 \\
\hline Female & $|855|$ & 45.3 \\
\hline \multicolumn{3}{|l|}{ Country of Birth } \\
\hline Oceanial & 25187 & 61.5 \\
\hline Europe & 8945 & 21.8 \\
\hline Asia & 4349 & 10.6 \\
\hline Africa & 773 & 1.9 \\
\hline \multicolumn{3}{|l|}{ Primary Language } \\
\hline English & 36517 & 89.2 \\
\hline Italian & 1158 & 2.8 \\
\hline Greek & 1009 & 2.5 \\
\hline Vietnamese & 428 & 1.0 \\
\hline \multicolumn{3}{|l|}{ Aboriginality ${ }^{2}$} \\
\hline Yes & 558 & 1.4 \\
\hline No & 40384 & 98.6 \\
\hline \multicolumn{3}{|l|}{ Marital Status } \\
\hline Single & 20025 & 48.9 \\
\hline Divorced/Separated & 6040 & 14.8 \\
\hline Married/Defacto & $|396|$ & 34.1 \\
\hline Unknown & 916 & 2.2 \\
\hline \multicolumn{3}{|l|}{ Interpreter } \\
\hline Yes & 3498 & 8.5 \\
\hline No & 37444 & 91.5 \\
\hline \multicolumn{3}{|l|}{ Pensioner ${ }^{3}$} \\
\hline Yes & 13309 & 32.5 \\
\hline No & 27633 & 67.5 \\
\hline \multicolumn{3}{|l|}{ Homeless } \\
\hline Yes & 1595 & 3.9 \\
\hline No & 39347 & 96.1 \\
\hline \multicolumn{3}{|l|}{ Religion } \\
\hline Religious Belief & 24168 & 59.0 \\
\hline None & 13449 & 32.8 \\
\hline Unknown & 3325 & 8.1 \\
\hline
\end{tabular}

Note. I. Oceania includes: Australia, New Zealand and surrounding islands. 2. Aboriginality is defined as the indigenous population. 3 . Pension Card entitlements include: age (65 and 0ver) and disability. 
Table 2: Visit characteristics of all patient visits to the emergency department from Ist January 2003 to 3 I st December 2004 (n = 64,147).

\begin{tabular}{|c|c|c|c|c|}
\hline Variable & No & $\%$ & & \\
\hline \multicolumn{5}{|l|}{ Arrival Transport } \\
\hline Ambulance & 21190 & 33 & & \\
\hline Police & 1135 & 1.8 & & \\
\hline Car & 7231 & 11.3 & & \\
\hline Public Transport & 4201 & 6.5 & & \\
\hline Unknown & 30390 & 47.4 & & \\
\hline \multicolumn{5}{|l|}{ Australasian Triage Code } \\
\hline I (seen immediately) & 863 & 1.3 & & \\
\hline 2 (seen within 10 minutes) & 5830 & 9.1 & & \\
\hline 3 (seen within 30 minutes) & 25344 & 39.5 & & \\
\hline 4 (seen within 60 minutes) & 27229 & 42.4 & & \\
\hline 5 (seen within 120 minutes). & 4881 & 7.6 & & \\
\hline \multicolumn{5}{|l|}{ Season } \\
\hline Summer & 16367 & 25.5 & & \\
\hline Autumn & 16044 & 25.0 & & \\
\hline Winter & 15559 & 24.3 & & \\
\hline Spring & 16177 & 25.2 & & \\
\hline \multicolumn{5}{|l|}{ Shift } \\
\hline AM shift (0726-1425) & 23142 & 36.1 & & \\
\hline PM shift (I426-2135) & 24620 & 38.4 & & \\
\hline ND shift (2I36-0725) & 16385 & 25.5 & & \\
\hline \multicolumn{5}{|l|}{ After Hours (170I-0859) } \\
\hline Yes & 34154 & 53.2 & & \\
\hline No & 29993 & 46.8 & & \\
\hline \multicolumn{5}{|l|}{ Attend Code(Sent in by) } \\
\hline Self or Family & 45593 & 71.1 & & \\
\hline Other & 8569 & 13.4 & & \\
\hline GP & 5071 & 7.9 & & \\
\hline Nursing Home & 252 & 0.4 & & \\
\hline Other Institution & 1510 & 2.4 & & \\
\hline \multicolumn{5}{|l|}{ Presenting Complaint } \\
\hline Injury & $|184|$ & 18.5 & & \\
\hline Mental Illness & 2980 & 4.6 & & \\
\hline Drug Misuse & 1119 & 1.7 & & \\
\hline Medical & $4577 \mid$ & 71.4 & & \\
\hline Other & 2436 & 3.8 & & \\
\hline \multicolumn{5}{|l|}{ Left Own Risk } \\
\hline Yes & 3372 & 5.3 & & \\
\hline No & 60775 & 94.7 & & \\
\hline \multicolumn{5}{|l|}{ Discharge Outcome } \\
\hline Admit & 15898 & 24.8 & & \\
\hline Transfer & 1708 & 2.7 & & \\
\hline Home & 42667 & 66.5 & & \\
\hline Nursing Home & 201 & 0.3 & & \\
\hline Return to Ward & 303 & 0.5 & & \\
\hline Variables & Min & $\operatorname{Max}$ & Mean (SD) & Median \\
\hline Time to be Seen (Minutes) & 0.0 & 852.7 & $46.5(58.7)$ & 25.1 \\
\hline Inpatient Length of Stay (Days) & 0.04 & 191.2 & $7.0(10.2)$ & 4.1 \\
\hline ED Length of Stay (Hours) & 0.0 & 96.0 & $4.6(4.8)$ & 3.4 \\
\hline
\end{tabular}

agreement for the category homeless or not homeless was $96.7 \%$ for 3 raters, 20 cases and 2 categories. The percentage of agreement for the level of homelessness was $73.3 \%$ for 3 raters, 20 cases and 5 categories. In 12 of the 20 cases all 3 raters agreed with the 5 categories and with the other 8 cases 2 of the raters agreed. The level of homelessness was the only variable that required an assessment from the abstractors. It was not difficult to assess that someone 
Table 3: Demographic characteristics of all patients who attended the emergency department by housing status from Ist January 2003 to 3 I st December $2004(n=40,942)$.

\begin{tabular}{lccc}
\hline Demographic Variable & Housing Status & \\
& Homeless $(\mathbf{n}=\mathbf{I}, \mathbf{5 9 5})$ & Non-homeless $(\mathbf{n}=\mathbf{3 9 , 3 4 7 )}$ & P value \\
\hline Indigenous & $106(6.6 \%)$ & $452(1.1 \%)$ & $<0.001$ \\
Single & $1145(71.8 \%)$ & $18880(48.0 \%)$ & $<0.001$ \\
Interpreter & $55(3.4 \%)$ & $3443(8.8 \%)$ & $<0.001$ \\
Pensioner & $1017(63.8 \%)$ & $12292(31.2 \%)$ & $<0.001$ \\
Male & $1186(74.4 \%)$ & $21205(53.9 \%)$ & $<0.001$ \\
\hline
\end{tabular}

Note. Chi-Square test undertaken of the hypothesis of equal proportions. Indigenous: includes Aboriginal or Torres Strait Islander. Marital Status: involves proportion with a single status. Interpreter: indicated if requested in the Patient Administration System for communication purposes. Pensioner: involves recipient of a government pension.

was homeless but there was a degree of difficulty in determining the level of homelessness.

\section{Primary Data Analysis}

All data were entered into a Microsoft Access database and were subsequently analyzed using SPSS, version 14.0 (Chicago, IL). The ED presentation data $(n=64,147)$ were examined by constructing a frequency cross-tabulation of re-presentation (yes/no) against each categorical explanatory variable (factor), and by constructing a table of means for each continuous explanatory variable (covariate). This information containing ED presentation data was aggregated into a patient dataset $(n=40,942)$ that contained the percentage of attendances resulting in representation for each patient. The patient data were examined by constructing a table of the mean percentage for each factor. Because of the unequal numbers of presentations per patient $(\min =1: \max =152)$, the percentage of all visits resulting in re-presentation was larger than the mean percentage calculated across patients, for each category of each factor. For example, if we consider patients who were pensioners $(n=28,660), 25.9 \%$ of their visits resulted in re-presentation, but the mean percentage calculated across these patients was $10.9 \%$. Because the probability of re-presentation is correlated between visits within a patient, neither of the above figures is an appropriate estimate of the true percentage, $p$. The percentage of all visits is an overestimate of $p$, because it gives equal weight to each visit, and so is inflated by patients with a large number of visits. The mean percentage across patients is an underestimate of $p$, because it gives equal weight to each patient, and so effectively ignores the additional information provided by the multiple visits of many patients.

We dealt with the potential problem of underestimation or overestimation of re-presentation by developing a generalized linear mixed model (GLMM) with a binomial distribution. This model uses all the data to estimate the correlation between visits within a patient, and gives an estimate of $p$ which gives an appropriate effective weighting to visits and patients. In the example involving pensioners, the estimate is $17.5 \%$, which is between the two percentages mentioned. For this example, the estimate is about half-way between but in other cases it can be much more toward one side, depending on the correlation for the group of interest. The GLMM used for this study was a logistic regression model with the patient variable fitted as a random effect to account for repeated presentations. The fitting of the model was performed using GenStat ( $8^{\text {th }}$ edition, VSN International, UK).

For each explanatory variable on its own, a GLMM was fitted with re-presentation (yes/no) as the response variable. The $P$-value for testing the hypothesis of no effect was determined by comparing the Wald statistic with the appropriate chi-square distribution. Variables for which the $P$-value was greater than 0.01 were excluded from further model fitting. All the remaining explanatory variables were entered into a backwards stepwise procedure, in which the least significant variable at each stage was progressively removed from the model, until all variables still in the model were significant at the 0.01 level. The 0.01 cut-off was chosen rather than the more common value of 0.05 because the large number of observations meant that a small $P$-value could arise from an inconsequential effect size.

The estimated parameters and standard errors from the final model were used to calculate adjusted odds ratio (OR) and associated 95\% confidence intervals for each explanatory variable. There were twelve of them - seven related to patient characteristics, and five related to ED visit characteristics. For explanatory variables not in the final model, unadjusted OR and 95\% confidence intervals were calculated. 
Table 4: Percentage of visits resulting in re-presentation to the emergency department and adjusted odds ratios for the final model by significant patient and emergency department visit characteristics I January 2003 to 3I December 2004.

\begin{tabular}{|c|c|c|c|c|}
\hline Explanatory Variable & All Visits \% $(n=64,147)$ & All Patients \% $(n=40,942)$ & \% Predicted by Model & Adjusted Odds Ratio (95\% Cl) \\
\hline Total Re-presentation & $18.0(n=11559)$ & $6.9(n=5894)$ & & \\
\hline \multicolumn{5}{|l|}{ Patient Characteristics } \\
\hline \multicolumn{5}{|l|}{ Homeless } \\
\hline No & $14.5(n=57458)$ & $6.3(n=39347)$ & 11.8 & Reference \\
\hline Yes & $47.8(n=6689)$ & $22.7(n=1595)$ & 34.7 & $3.09(2.83,3.36)$ \\
\hline \multicolumn{5}{|l|}{ Pensioner } \\
\hline No & $11.6(n=35487)$ & $5.0(n=27633)$ & 9.5 & Reference \\
\hline Yes & $25.9(n=28660)$ & $10.9(n=13309)$ & 18.5 & $1.73(1.63,1.84)$ \\
\hline \multicolumn{5}{|l|}{ Gender } \\
\hline Female & $16.2(n=28328)$ & $6.3(n=|855|)$ & 11.9 & Reference \\
\hline Male & $19.5(n=35819)$ & $7.4(n=22391)$ & 13.7 & $1.16(1.10,1.22)$ \\
\hline \multicolumn{5}{|l|}{ Age } \\
\hline 25 years and under & $11.5(n=11162)$ & $4.8(n=8745)$ & 9.2 & Reference \\
\hline$>25$ years & $19.4(n=52985)$ & $7.5(n=32197)$ & 13.8 & $1.21(1.12,1.32)$ \\
\hline \multicolumn{5}{|l|}{ Marital Status } \\
\hline Single & $18.0(n=30321)$ & $6.4(n=20025)$ & 12.4 & Reference \\
\hline No Longer Married & $22.6(n=11709)$ & $9.3(n=6040)$ & 16.2 & $1.13(1.04,1.22)$ \\
\hline Married/de facto & $16.3(n=21058)$ & $6.8(n=13961)$ & 12.4 & $1.04(0.97,1.11)$ \\
\hline Unknown & $6.9(n=1059)$ & $2.9(n=916)$ & 5.6 & $0.43(0.33,0.56)$ \\
\hline \multicolumn{5}{|l|}{ Interpreter Required } \\
\hline No & $17.6(n=57 \mid 80)$ & $6.3(n=37444)$ & 12.5 & Reference \\
\hline Yes & $21.2(n=6967)$ & $9.4(n=3498)$ & 16.6 & $1.13(1.04,1.22)$ \\
\hline \multicolumn{5}{|l|}{ ED Visit Characteristics After Hours } \\
\hline $0900-1700$ & $17.3(n=29993)$ & & 12.5 & Reference \\
\hline $1701-0859$ & $18.6(n=34154)$ & & 13.3 & $1.11(1.06,1.17)$ \\
\hline \multicolumn{5}{|l|}{ Attendance Source } \\
\hline Other Institutions (Hospitals/Correctional) & $8.9(n=1510)$ & & 7.7 & Reference \\
\hline Community Nurse & $20.1(n=2861)$ & & 12.4 & $1.31(1.06,1.63)$ \\
\hline Hospital Service (Out/Inpatient, ED Review) & $26.4(n=269)$ & & 14.4 & $1.83(1.28,2.62)$ \\
\hline Crisis Assessment Team & $36.4(n=22)$ & & 24.0 & $2.97(1.05,8.4 I)$ \\
\hline Self/Family/Friends & $18.3(n=45593)$ & & 12.7 & $1.46(1.21,1.77)$ \\
\hline General Practitioner & $15.7(n=507 \mid)$ & & 13.1 & $1.46(1.19,1.80)$ \\
\hline Nursing Home & $15.9(n=252)$ & & 13.2 & $1.09(0.72,1.66)$ \\
\hline Other & $18.5(n=8569)$ & & 12.6 & $1.42(1.16,1.73)$ \\
\hline \multicolumn{5}{|l|}{ Discharge Outcome } \\
\hline Home & $17.9(n=42667)$ & & 13.0 & Reference \\
\hline Transfer Other Facility & $8.1(n=1708)$ & & 6.3 & $0.43(0.36,0.53)$ \\
\hline Left Unseen & $25.1(n=2654)$ & & 15.8 & $1.19(1.06,1.33)$ \\
\hline Left Part Treatment & $33.0(n=716)$ & & 21.2 & $1.64(1.36,1.99)$ \\
\hline Admit & $17.6(n=15898)$ & & 12.8 & $0.85(0.81,0.90)$ \\
\hline Residential Care Facility & $31.8(n=201)$ & & 21.9 & $1.46(1.03,2.06)$ \\
\hline Return to Ward & $32.3(n=303)$ & & 18.4 & $1.16(0.88,1.53)$ \\
\hline \multicolumn{5}{|l|}{ Presenting Complaint } \\
\hline Injury & $11.3(n=1184 \mid)$ & & 9.4 & Reference \\
\hline Mental Illness & $28.5(n=2980)$ & & 18.5 & $1.65(1.47,1.86)$ \\
\hline Drug Misuse & $36.6(n=1119)$ & & 14.4 & $1.20(0.99,1.46)$ \\
\hline Medical/Other & $18.6(n=48207)$ & & 13.6 & $1.38(1.28,1.48)$ \\
\hline \multicolumn{4}{|l|}{ ED Length of Stay (Hours) } & $1.01(1.01,1.02)$ \\
\hline
\end{tabular}


Although the housing status comprised five categories, there were no significant differences between the four homeless levels in terms of their re-presentation percentages, so in the final model they were combined into a single category. However, because of the importance of this variable to our study, a separate model was fitted with all five categories, and adjusted OR and confidence intervals calculated.

\section{Results}

A total of 64,147 emergency department visits by 40,942 individuals occurred between 1 January 2003 and 31 December 2004 inclusive. The mean ED length of stay for the cohort was 4.60 hours $(\mathrm{SD}=4.78)$ and the mean inpatient length of stay was 7.03 days $(S D=10.22)$. The number of presentations varied from 1 to 152 per patient with the mean number being 1.75 . Of the study group, $54.7 \%(\mathrm{n}=22,391)$ were male, $48.9 \%(\mathrm{n}=20,025)$ were single and $32.5 \%(\mathrm{n}=13,309)$ were receiving a pension and $1.4 \%(\mathrm{n}=558)$ were indigenous. The mean age was $45(\mathrm{SD}=21)$, median 40 , with the range of age from 1 to 107. The percentage of indigenous people re-presenting to the ED was higher than the percentage in the general population, since $0.6 \%(n=29,683)$ of people residing in the state are of an indigenous background [50]. Those with a European or Asian country of birth made up $32.4 \%(\mathrm{n}=$ $13,294)$ of the study group with $26.3 \%(n=3,498)$ of this population requiring an interpreter on presentation to the ED. Australia has a relatively large proportion of immigrants making up $24 \%$ of the population with a quarter of the immigrants born in Asia [51].

Table 1 shows the demographic characteristics of patients who presented to the ED for the study period. Homeless people accounted for 3.9\% $(\mathrm{n}=1,595)$ of the total study population and $10.4 \%(6,689)$ of all presentations and $27.7 \%(n=3,199)$ of all re-presentations. Table 2 shows the visit characteristics of patients who presented to the ED during the two-year period. Those patients who presented after hours represented $53.2 \%(n=34,254)$ of the total presentations. Patients who left at own risk $(\mathrm{n}=$ 3,372 ) represented $5.3 \%$ of all the presentations. Table 3 shows the demographic characteristics of all patients who attended the ED during the study period by housing status (homeless/non homeless) that are significantly different with a $\mathrm{p}$ value $<0.001$. The fact that homeless people had a significantly higher incidence of being on the pension and a significantly lower incidence of accessing an interpreter reveals additional issues of vulnerability associated with homelessness. Due to the limited information in medical records it was not possible to explore the utilisation of interpreting services.

The rate of re-presentation for the total population was $18.0 \%(n=11,559)$ of visits and $14.4 \%(n=5,894)$ of patients. The mean time to re-presentation was 7.9 days and the median was 6.0 days. More than half of all re-presentations occurred within one week of discharge from the ED $(60.8 \% ; n=6,873)$, and more than three-quarters represented within two weeks of the initial presentation $(80.9 \% ; \mathrm{n}=9,151)$. Of those patients who re-presented within one week, $66.4 \%(\mathrm{n}=7,506)$ were initially discharged home and 55.3\% $(\mathrm{n}=6,253)$ attended the ED after business hours. A small group re-presented while an inpatient $(n=251)$ and they were excluded from these figures.

The patient variables that significantly influenced re-presentation of patients to the ED are shown in Table 4. Most notably, housing status (being homeless) and source of income (being a recipient of a government pension) were associated with increased odds of re-presentation (adjusted OR 3.09; 95\% CI, 2.86 to 3.36; adjusted OR $1.73 ; 95 \%$ CI, 1.63 to 1.84 respectively). In addition, our analysis showed that a presenting complaint of mental illness increased the odds of re-presentation by 1.65 times compared to injury (95\% CI, 1.47 to 1.86 ). Where patients left part-way through treatment they had 1.64 times greater odds of re-presenting than if they completed treatment and were discharged home (95\% CI, 1.36 to 1.99). Being discharged to a residential care facility increased the odds of re-presentation by 1.46 times when compared to being discharged home (95\% CI, 1.03 to 2.06).

While housing status (homeless) was highly significant in determining the likelihood of re-presentation to the ED, within the levels of homelessness, there were no significant differences between the primary, secondary, tertiary and marginalized housing groups. Table 5 shows the number and percentage of visits resulting in re-presentation and adjusted odds ratios by housing status.

\section{Discussion}

Emergency re-presentations were found to account for almost one-fifth $(17.4 \%)$ of all ED visits. This proportion is slightly higher than overall hospital re-admission rates, which have been reported to range from 5 to 14 percent in general populations [52-54] and from 12 to 16 percent in geriatric populations $[44,55,56]$.

The pattern of ED re-presentation described in this study showed that rates clustered around one week after the first visit and fell rapidly thereafter. This result is also similar to work on patterns of hospital re-admission [44], but it is not possible to tell whether early ED re-presentations are due to factors that are amenable to targeted interventions or the result of other non-preventable factors including the normal progression of disease. 
Table 5: Percentage of visits and of patients resulting in re-presentation and adjusted odds ratios by housing status.

\begin{tabular}{|c|c|c|c|c|}
\hline Explanatory Variable & All Visits $(n=64,147)$ & All Patients $(n=40,942)$ & \% Predicted by Model & $\begin{array}{c}\text { Adjusted Odds Ratio } \\
(95 \% \mathrm{Cl})\end{array}$ \\
\hline \multicolumn{5}{|l|}{ Housing status } \\
\hline Primary homeless & $43.8(n=1097)$ & $19.7(n=369)$ & 32.0 & $3.54(3.00,4.21)$ \\
\hline Secondary homeless & $56.7(n=1279)$ & $24.8(n=263)$ & 38.6 & $4.68(4.00,5.62)$ \\
\hline Tertiary homeless & $43.5(n=1858)$ & $23.3(n=44 I)$ & 34.3 & $3.90(3.38,4.49)$ \\
\hline Marginalized housing & $48.3(n=2455)$ & $21.8(n=522)$ & 34.5 & $3.93(3.45,4.48)$ \\
\hline Stable housing & $14.5(n=57458)$ & $5.9(n=39347)$ & 11.8 & Reference \\
\hline
\end{tabular}

Note. Primary homeless: people living on the streets or in squats. Secondary homeless: people living in crisis accommodation. Tertiary homeless: people living in boarding houses. Marginalized housing: those people residing in public housing requiring rental assistance or those with other unstable rental arrangements. Stable, non homeless: people living in permanent accommodation.

Our study found that the characteristics influencing representation to the ED included a range of socio-economic factors; in particular housing status and receiving a government pension were identified as significant risk factors for re-presentation. These findings are consistent with work on frequent ED use $[5,10,13,16,18,19,42]$ but are new to our understanding of factors influencing ED representation.

While a homeless housing status was highly significant in determining the likelihood of re-presentation to the $\mathrm{ED}$, within the levels of homelessness there was no significant difference between the primary, secondary, tertiary and marginalized housing categories. This finding has important clinical implications in trying to identify patients at risk of re-presentation. It may be easier to identify someone living on the streets, but those patients who have an address but fit into a marginalized housing category are not so easily identified by hospital staff, even though they are equally at risk.

To date interventions designed to decrease ED attendances have involved two main strategies; increasing referrals to alternative sources of care, such as general practices [57-59], and referral to care coordination programs and community based support services for those people at risk [23]. However, evaluation of these strategies has produced mixed results $[23,60]$. For example, increasing the number and availability of general practice clinics, especially in close proximity to the $\mathrm{ED}$, is one approach that has been suggested to decrease ED demand [59]. This approach has, by in large, not been successful because many ED patients, even those classified as non-urgent, are more complex and require longer consultation times than general practice patients [59]. In addition, people who attend EDs with less urgent problems have higher hospital admission rates than those who attend general practices [61].

Care co-ordination aims to decrease ED re-presentation rates [23]. Using this approach, patients are screened to determine their likelihood of re-presenting to hospital at ED triage. Risk factors for re-presentation commonly include; age >65 years, living alone, significant care responsibilities, receiving community services and self care problems [59]. Diagnostic categories for heart failure, chronic obstructive pulmonary disease (COPD) and asthma have been found to increase the risk of hospital readmission and high levels of deprivation, that is low socio-economic status, is significantly and independently associated with increased odds of emergency medical readmission [45].

This research was conducted at a single inner-city ED in Australia, thus these findings cannot be generalized to other locations. However, since we used data elements mandated for reporting to the EMD, this work has the potential to be replicated in other Australian EDs and internationally. Although there is potential for national replication the Australian health care system does differ substantially from other countries and therefore it may not be possible to directly compare rates and patterns of ED re-presentation to those found elsewhere in the world.

The study only had data for presentations to the targeted hospital and it was not possible to identify those patients who may have presented to other hospitals after attending the study hospital. Patients who died as a discharge outcome were excluded from the study but the data on subsequent deaths occurring after discharge were unreliable due to incomplete data. These individuals were not known and therefore not excluded.

A further factor limiting comparison between ED re-presentation rates is the lack of information currently collected on housing status by EDs. Our study could identify housing status as a factor significantly influencing re-presentation rates since this information was available on the hospital ED PAS database and confirmed by review of patients' medical records. The data collection of other EDs through the EMD does not routinely include this crucial information. One possible reason for not including this 
information in the EMD may relate to the different ways in which homelessness is understood and defined [62].

Although the study was a retrospective analysis, we included the total population for a defined period of time and aside from death, there were no exclusions. Since the data used were mandated for reporting through the EMD the data set was relatively complete and objective.

\section{Conclusion}

A definition for ED re-presentation and housing status has clinical relevance to assist in early recognition of risk factors and targeting specific resources. The fact that homeless people have a significantly higher incidence of being on the pension and a significantly lower incidence of accessing an interpreter reveals additional issues of vulnerability associated with homelessness.

Many people present to the ED after hours and this makes accessing and referral to services other than those of a medical nature more difficult. More than $50 \%$ of patients in our study who re-presented in the first week did so after hours. This finding has implications for referral practices. Service provision for patients who not only have a medical condition but are homeless is complex but unless a hospital system develops strategies for early recognition and referral with a broader definition of homelessness, patients will continue to re-present with ongoing issues that may not be confined to their medical condition.

\section{Competing interests}

There have been no previous publications of this study and there is no perceived conflict of interest or copyright constraints. The authors declare that they have no competing interests.

\section{Authors' contributions}

$\mathrm{EM}, \mathrm{MG}$ and $\mathrm{AD}$ conceived the study, designed the method, and obtained research funding. EM and MG are the head supervisors, $\mathrm{AD}$ was a co-supervisor and a clinical expert and GM is the $\mathrm{PhD}$ candidate. $\mathrm{EM}, \mathrm{MG}$ and $\mathrm{AD}$ supervised the conduct of the study and data collection. GM undertook collection and overseeing data abstraction, development of abstractor tools and analysis, including quality control. GH provided statistical advice on study design and supervised analysis of data. MG and GM drafted the manuscript, and all authors contributed substantially to its revision and approved the final manuscript. GM takes responsibility for the paper as a whole. All authors have read and approved the final manuscript.

\section{Acknowledgements}

We would like to thank the Australian Research Council Linkage Project Scheme for funding the PhD Scholarship and St. Vincent's Health for financial support.

\section{References}

I. Malone R E: Heavy users of emergency services: social construction of a policy problem. Soc Sci Med 1995, 40:469-477.

2. Mandelberg JH, Kuhn RE, Kohn MA: Epidemiologic analysis of an urban public emergency department's frequent users. Acad Emerg Med 2000, 7:637-646.

3. Ruger JP, Richter CJ, Spitznagel EL, Lewis LM: Analysis of costs, length of stay, and utilisation of emergency department services by frequent users: implications for health policy. Acad Emerg Med 2004, I I: I3 I I-1317.

4. Zoot CJ, Moore FD: High-cost users of medical care. N Engl J Med 1980, 302:996-1002.

5. Baker D, Stevens C, Brook R: Regular source of ambulatory care and medical utilization by patients presenting to a public emergency department. JAMA 1994, 271:1909-1912.

6. Stern R, Weissman P, Epstein A: The emergency department as a pathway to admission for poor and high cost patients. JAMA 1991, 226:238-243.

7. Richardson LD, Hwang U: Access to care: a review of the emergency medicine literature. Acad Emerg Med 200I, 8( I I): 1030-1036.

8. Dwyer J, Jackson T: Literature review: Integrated bed and patient management. [http://www.health.vic.gov.au/emergency/ bgdocs/litrview.pdf].

9. Pope D, Fernandes CM, Bouthillette F, Etherington J: Frequent users of the emergency department: a program to improve care and reduce visits. CMAJ 2000, 1 62(7): $1017-1020$.

10. Olsson $M$, Hansagi $H$ : Repeated use of the emergency department: qualitative study of the patient's perspective. Emerg Med J 200I, I 8:430-434.

II. Byrne M, Plunkett P, McGee H, Murray A, Bury G: Frequent attenders to an emergency department: A study of primary health care use, medical profile, and psycho-social characteristics. Ann Emerg Med 2003, 41:309-318.

12. Dent AW, Phillips GA, Chenhall AJ, McGregor LR: The heaviest repeat users of an inner city emergency department are not general practice patients. Emerg Med (Fremantle) 2003, I5(4):322-329.

13. Salazar A, Bardes I, Juan A, Olonoa N, Sabida M, Corbella X: High mortality rates from medical problems of frequent emergency department users at a university hospital tertiary care centre. Eur J Emerg Med 2005, I 2:2-5.

14. Fulde GW, Duffy M: Emergency Department frequent flyers: unnecessary load or lifeline? Med J Aust 2006, I 84:595.

15. Kennedy D, Ardagh M: Frequent attenders at Christchurch Hospital's emergency department: a 4 year study of attendance patterns. N Z Med J 2004, I I 7:U87I.

16. Malone R E: Whither the Almshouse? Overutilisation and the role of the emergency department. J Health Polit Policy Law 1998, 23:795-832.

17. Eagle DJ, Rideout E, Price P, McCann C, Wonnacott E: Misuse of the emergency department by the elderly population: myth or reality. J Emerg Nurs 1993, 19:212-218.

18. Murphy AW, Leonard C, Plunkett PK, Brazier H, Conroy R, Lynam F, Bury $G$ : Characteristics of attenders and their attendances at an urban accident and emergency department over a one year period. J Accid Emerg Med 1999, I 6(6):425-427.

19. Murphy AW: Inappropriate attenders at accident and emergency departments $I$ : definition, incidence and reasons for attendance. Fam Pract 1998, 15:23-31.

20. D'Amore J, Hung O, Chiang W, Goldfrank L: The Epidemiology of the Homeless Population and Its Impact on an Urban Emergency Department. Acad Emerg Med 200I, 8: I05I-I055.

21. Lang T, Davido A, Diakité B, Agay E, Viel JF, Flicoteaux B: Using the hospital emergency department as a regular source of care. Eur J Epidemiol 1997, 13:223-228.

22. Chan DK, Chong R, Basilikas J, Mathie M, Hung WT: Survey of major chronic illnesses and hospital admissions via the emergency department in a randomized older population in Randwick, Australia. Emerg Med (Fremantle) 2002, I 4(4):387-392.

23. Moss J, Flower C, Houghton L, Moss D, Nielsen D, Taylor D: A multidisciplinary Care Coordination Team improves emergency department discharge planning practice. Med J Aust 2002, I 77:435-439.

24. Kushel M, Perry S, Bangsberg D, Clark R, Moss A: Emergency department use among the homeless and marginally 
housed: Results from a community-based study. Am J Public Health 2002, 92:778.

25. Bergh $H$, Baigi $A$, Marklund $B$ : Consultations for injuries by frequent attenders are found to be medically appropriate from a general practitioners' perspective. Scan J Public Healt 2005, 33:228-232.

26. O'Dwyer F, Bodiwala G: Unscheduled return visits by patients to the accident and emergency department. Archives of Emergency Medicine I991, 8:196-200.

27. Keith K, Bocka J, Kobernick M, Krome R, Michigan R, Michigan W: Emergency Department Revisits. Annals of Emergency Medicine 1989, 18:964-968.

28. Friedmann PD, Jin L, Karrison TG, Cox Hayley D, Mulliken R, Walter J, Chin MH: Early Revisit, Hospitalization, or Death among older persons discharged from the ED. The American Journal of Emergency Medicine 200I, 19:125-129.

29. McCusker J, Cardin S, Bellavance F, Belzile E: Return to the emergency department among elders: patterns and predictors. Academic Emergency Medicine 2000, 7:249-259.

30. McCusker J, Cardin S, Bellavance F, Belzile E: Hospital characteristics and emergency department care of older patients are associated with return visits. Academic Emergency Medicine 2007, I 4:426-433.

31. McCusker J, Bellavance F, Cardin S, Belzile E, Verdon J: Prediction of hospital utilization among elderly patients during the 6 months after an emergency department visit. Annals of Emergency Medicine 2000, 36:438-445.

32. Fan J, Worster A, Fernandes C: Predictive validity of the Triage Risk Screening Tool for elderly patients in a Canadian emergency department. American Journal of Emergency Medicine 2006 24:540-544.

33. Caplan GA, Brown A, Croker WD, Doolan J: Risk of admission within 4 weeks of discharge of elderly patients from the emergency department--the DEED study. Age and Ageing 1998, 27:697-702.

34. Aminzadeh F, Dalziel WB: Older adults in the emergency department: A systematic review of patterns of use, adverse outcomes, and effectiveness of interventions. Annals of Emergency Medicine 2002, 39:238-247.

35. Meldon SW, Mion LC, Palmer RM, Drew BL, Connor JT, Lewicki LI, Bass DM, Emerman CL: A brief risk-stratification tool to predict repeat emergency department visits and hospitalizations in older patients discharged from the emergency department. Acad Emerg 2003, 10(3):224-32.

36. McCusker J, Karp I, Cardin S, Durand P, Morin J: Determinant of Emergency Department Visits by Older Adults: A Systematic Review. Academic Emergency Medicine 2003, 10:1362-1370.

37. Hider P, Kirk R, Bidwell S, Weir R: Emergency Department Attendance. A critical appraisal of the literature. :Critical appraisal of literature [http://nzhta.chmeds.ac.nz/publica tions.htm\#review]

38. Schneider KC, Dove HG: High users of VA emergency room facilities: are outpatients abusing the system or is the system abusing them? Inquiry 1983, 20:57-64.

39. Andren KG, Rosenquist U: Heavy users of an emergency department: psycho-social and medical characteristics, other health care contacts and the effect of a hospital social worker intervention. Soc Sci Med 1985, 21:76 I-770.

40. Andren KG, Rosenquist $U$ : Heavy users of an emergency department - a two year follow-up study. Soc Sci Med 1987, 25:825-831.

41. Purdie FR, Honigman B, Rosen P: The chronic emergency department patient. Ann Emerg Med I98I, 10:298-30I.

42. Okin RL, Boccellari A, Azocar F, Shumway M, O'Brien K, Gleb A, Kohn M, Harding P, Wachsmuth C: The effects of clinical case management on hospital service use among ED frequent users. Am J Emerg Med 2000, 18:603-608.

43. Phillips G, Brophy D, Weiland T, Chenhall A, Dent A: The effect of multidisciplinary case management on selected outcomes for frequent attenders at an emergency department. Med J Aust 2006, 184:602-606.

44. Benbassat J, Taragin M: Hospital Readmissions as a Measure of Quality of Health Care: Advantages and Limitations. Arch Intern Med 2000, 160:1074-108I.

45. Lyratzopoulos G, Havely D, Gemmell I, Cook GA: Factors influencing emergency medical readmission risk in the UK district general hospital: A prospective study. BMC Emerg Med 2005 , 5:I.

46. Nuñez S, Hexdall A, Aguirre-Jaime A: Unscheduled returns to the emergency department: an outcome of medical errors? Qual Saf Health Care 2006, I 5: 102- 108.

47. Hu SC: Analysis of patient revisits to the emergency department. The American Journal of Emergency Medicine 1992, 10:366-370.

48. Victorian Department of Human Services: Victorian Emergency Minimum Dataset (VEMD) Manual. 9th, July 2004 edition. [http://www.health.vic.gov.au/hdss/archive/vemd/2004/manual/ index.htm].

49. Chamberlain C, MacKenzie D: Counting the Homeless. Commonwealth of Australia, Australian Bureau of Statistics; 200 I.

50. Australian Bureau of Statistics: Experimental Estimates and Projections, Aboriginal and Torres Strait Islander Australians, 1991 to 2009. [http:www.abs.gov.aAUSSTATabs@.nsLooku3238.0Explanatory\%t99 1\%20t202009? Open Docu ment].

51. Australian Bureau of Statistics: Australian Social Trends, 2001. [http://www.abs.gov.au/AUSSTATS/abs@.nsf/

$7 d|2 \mathrm{~b} 0 \mathrm{f} 6763 \mathrm{c} 78 \mathrm{caca} 25706| 00 \mid \mathrm{cc} 588 /$

964f93de8bb5c425ca2570ec000bf8f8! OpenDocument].

52. Corrigan JM, Kazandjian VA: Characteristics of multiple admissions. J Am Med Rec Assoc 1991, 62(3):37-47.

53. Bean P, Waldron K: Readmission study leads to continuum of care. Nurs Manage 1995, 26(9):65, 67-8.

54. Einstadter D, Cebul RD, Franta R: Effect of a Nurse Case Manager on Postdischarge Follow-Up. J Gen Int Med 1996, I I:684-688.

55. Sibbritt DW: Validation of a $\mathbf{2 8}$ day interval between discharge and readmission for emergency readmission rates. I Qual Clin Pract 1995, I 5(4):2II-220.

56. FrankI SE, Breeling JL, Goldman L: Preventability of emergent hospital readmission. Am I Med I991, 90:667-674.

57. Coleman P, Irons R, Nicholl J: Will alternative immediate care services reduce demands for non-urgent treatment at accident and emergency departments? Emerg Med J 200I, I 8:482-487.

58. Australasian College for Emergency Medicine: Access block and overcrowding in emergency departments. [http:// www.acem.org.au/media/Access Blockl.pdf].

59. Australasian College for Emergency Medicine: The relationship between emergency department overcrowding and alternative after-hours GP services. [http://www.medeserv.com.au/ acem/open/documents/after hoursgp.pdfl.

60. McCusker J, Dendukuri N, Tousignant P, Verdon J, Poulin de Courval L, Belzile E: Rapid two-stage emergency department intervention for seniors: impact on continuity of care. Acad Emerg Med 2003, 10:233-243

61. Australasian College for Emergency Medicine: Urban emergency services ATS 4 and 5 patients. [http://www.acem.org.au/media/ ats 45 factsheet.pdf].

62. Chamberlain C: The Data Challenges Ahead. Parity 2004 I 7:54-55.

\section{Pre-publication history}

The pre-publication history for this paper can be accessed here:

http://www.biomedcentral.com/1471-2458/7/320/pre pub 